\title{
Effects of accessory olfactory bulb lesions on the sexual behavior of male mice*
}

\author{
ANTHONY COOPER \\ Miami University, Oxford, Ohio 45056
}

\begin{abstract}
Two groups of sexually inexperienced male $\mathrm{C} 57 \mathrm{BL} / 6 \mathrm{~J}$ mice received limited lesions to their olfactory bulbs. One group received bilateral lesions in the area of the accessory olfactory bulbs, the other received lesions of similar size, but positioned more anteriorly. Subsequent to the operation, the animals of both groups were found to exhibit lower levels of sexual behavior than did a control group. Although no effect specific to the lesioning of the accessory bulbs was found, the study showed that olfactory bulb lesions of very limited extent can disrupt the sexual behavior of the male mouse without causing the animal to become anosmic.
\end{abstract}

Removal of, or extensive damage to the olfactory bulbs of male mice has been found to eliminate their mating behavior. (Rowe \& Edwards, 1972) This effect is due to central nervous system damage, rather than anosmia per se, because male mice rendered anosmic by the application of zinc sulplate to the olfactory mucosa show unimpaired sexual behavior (Rowe \& Smith, 1972).

It should be possible to produce limited olfactory bulb lesions in mice, affecting sexual behavior without producing anosmia. One site for such lesions could be the accessory olfactory bulbs, lying in the dorsal part of the posterior half of the main bulbs. The accessory bulbs have been implicated in the control of sexual behavior by Winans and Scalia (1970), who report connections from these to the medial amygdaloid nucleus, medial preoptic, and medial hypothalamus. Damage to the accessory bulbs would not necessarily produce anosmia, as the olfactory nerves enter the bulbs anteroventrally. The aim of this study was to investigate the effects of lesions to the accessory olfactory bulbs on the sexual behavior of male mice. Previous studies in this area have concerned themselves solely with the consummatory stages of sexual behavior (e.g., mounting), although these comprise only a small fraction of the overall pattern of sexual behavior. The present study, therefore, attempted to examine in more detail any deficits in sexual behavior resulting from the lesions.

\section{METHOD}

Ss were twenty-five sexually inexperienced male mice of the inbred $\mathrm{C} 57 \mathrm{BL} / 6 \mathrm{~J}$ strain. At the time of testing, they were between 90 and 120 days old.

Ss were divided into three treatment groups. Group AOB $(N=8)$ received bilateral lesions to the olfactory bulbs in the area of the accessory bulbs. Group $\mathrm{OB}(\mathrm{N}=8)$ received lesions of similar extent, but to a more anterior area of the bulbs. Group $\mathrm{UN}(\mathrm{N}=9)$ received no surgical treatment.

*Sponsored by Edward Simmel, who takes full editorial responsibility.
Operations were carried out under sodium pentobarbitol anesthesia. A longitudinal incision was made in the skin over the frontal bone, the skull was scraped, and burr-holes were drilled to expose the olfactory bulbs. The dorsal part of the bulb was a spirated, either posteriorly (Group AOB) or anteriorly (Group OB), and after bleeding had ceased, bone wax was packed into the holes in the skull, and the skin was sutured. Two weeks were allowed between surgery and testing. The males were tested with mature $\mathrm{C} 57 \mathrm{BL} / 6 \mathrm{~J}$ females. These were housed together in a large group, a mature male being present to regulate their estrous cycles (Whitten, 1956). Vaginal smears were taken daily, estrous females being used in the test of mating behavior. Testing took place in rectangular $45 \times 30 \mathrm{~cm}$ arena, with $30-\mathrm{cm}$ sides, under the illumination of a $40-\mathrm{W}$ red light, suspended $60 \mathrm{~cm}$ vertically above the center of the arena. A thin layer of clean bedding lined the arena floor. The male was introduced into the arena, followed $15 \mathrm{~min}$ later by the female, and observations were made of their behavior for $60 \mathrm{~min}$. Each male received three such tests, at 5-day intervals. The following behaviors were noted. (1) Latency of first contact between the mice. (2) Latency of the male's first chase of the female. (3) Number of male-initiated contacts. (4) Number of female-initiated contacts. (5) Number of chases. (6) Number of genital investigations made by the male. (7) Occurrence and number of mounts.

The males were also tested for anosmia. Each was food deprived for $24 \mathrm{~h}$, then removed from its home cage. A small quantity of peanut butter was buried in the bedding of the home cage, to a depth of about $1 / 2$ in. The mouse was returned to its cage, and the time taken to locate the peanut butter was recorded. After behavioral testing, all Ss were killed, and their brains were removed and examined macroscopically and histologically.

\section{RESULTS}

The data were analyzed using the Kruskal-Wallis one-way analysis of variance, Mann-Whitney U-tests, and the Wilcoxon test. No differences were found over trials for any group, therefore, a mean score per trial for each animal was used for analysis. Table 1 summarizes the data. No significant differences were found between the groups on the measures of (1) Latency of first contact $(\mathrm{H}=2.83)$; (2) Latency of first chase $(\mathrm{H}=0.87)$; (3) Number of male initiated contacts $(H=5.67)$, although the intergroup differences on this measure 
Table 1

Mating Behavior of Male Mice

\begin{tabular}{lccc}
\hline Group & AOB & OB & UN \\
\hline $\begin{array}{l}\text { Mean latency of first con- } \\
\text { tact between mice (sec) }\end{array}$ & 7.1 & 9.2 & 6.3 \\
$\begin{array}{l}\text { Mean latency of the } \\
\text { male's first chase of } \\
\text { the females (sec) }\end{array}$ & 47.0 & 94.9 & 53.0 \\
$\begin{array}{l}\text { Mean number of male- } \\
\text { initiated contacts }\end{array}$ & 101.7 & 87.5 & 126.9 \\
$\begin{array}{l}\text { Mean number of female- } \\
\text { initiated contacts }\end{array}$ & 42.4 & 34.6 & 42.3 \\
$\begin{array}{l}\text { Mean number of chases } \\
\begin{array}{l}\text { Mean number of genital } \\
\text { investigations made }\end{array}\end{array}$ & 7.6 & 2.6 & 18.0 \\
$\begin{array}{l}\text { by male } \\
\text { Percent mounting }\end{array}$ & 21.8 & 11.3 & 52.7 \\
\hline
\end{tabular}

approached significance at $p=0.05$; and (4) Number of female-initiated contacts $(\mathrm{H}=2.48)$.

Both Group AOB and OB animals showed a lower frequency of chases than did Group UN animals, and Group OB animals scored significantly lower than Group AOB animals on this measure. (AOB/UN U $=16$ $\mathrm{p}<.05, \mathrm{OB} / \mathrm{UN} \mathrm{U}=4 \mathrm{p}<.01, \mathrm{AOB} / \mathrm{OB} \mathrm{U}=10$ $\mathrm{p}<.05)$.

Animals of Groups $\mathrm{AOB}$ and $\mathrm{OB}$ also showed a lower frequency of genital investigation than did Group UN animals, again Group OB differed significantly from Group AOB. (AOB/UN U $=12 \mathrm{p}<.05, \mathrm{OB} / \mathrm{UN} \mathrm{U}=8$ $\mathrm{p}<.05, \mathrm{AOB} / \mathrm{OB} U=13 \mathrm{p}<.05)$.

Group $A O B$ animals showed no mounting, and this behavior was only seen in a single Group OB animal, during one trial. Only two Group UN animals failed to mount during at least one trial.

Animals of all groups were able to locate the buried peanut butter-intergroup differences were not significant $(\mathrm{H}=3.05)$.

Macroscopic examination of the brains of Groups $A O B$ and $O B$ animals revealed lesions of limited extent, involving removal of about $20 \%$ of the bulbs. Damage was usually evenly distributed between the two bulbs.

Histological examination of the remaining bulb tissue of Group AOB animals revealed that in six of the eight mice the accessory olfactory bulbs had been completely removed; unilateral fragments of the accessory bulb survived in the other two animals.

\section{DISCUSSION}

The seemingly normal ability of Group AOB and OB animals to locate the buried peanut butter argues against their having incurred a significant reduction of olfactory acuity.

Animals from both of these groups showed reduced levels of sexual activity, and, as the deficit incurred by Group OB mice was as severe as that found in those of Group AOB, no effect resulting specifically from accessory olfactory bulbs damage is apparent.

The present study indicates that olfactory bulb lesions of very limited extent can affect the sexual behavior of male mice. This finding is at variance with the earlier report of Rowe and Edward (1972) who found that those mice which contined to mate postoperatively had incurred only minor damage to the olfactory bulbs, and also with the opinion of Rowe and Smith (1973) that lesions involving less than $50 \%$ of the bulbs are unlikely to impair sexual behavior.

The reduced frequency of chasing and genital investigation shown by Group OB compared with Group AOB animals might be explained in motivational terms, in changes of activity level of the animals, not measured in this study, or in changes of olfactory acuity, undetected in the peanut butter location test. If this is the case, then it is possible that the olfactory sense, while unimportant to consummatory copulatory activity, might play a role in the earlier stages of the sexual behavior of the male mouse.

\section{REFERENCES}

Rowe, F. A. \& Edwards, D. A. "Olfactory bulbs removal: influences on the mating behavior of male mice." Physiology \& Behavior, 1972, 8, 37-41.

Rowe, F. A., \& Smith, W. E. Effects of peripherally induced anosmia on mating behavior of male mice. Psychonomic Science, 1972, $27(1), 33-34$.

Rowe, F. A., \& Smith, W. E. Simultaneous and Successive Olfactory Bulb Removal: Influences on the mating behavior of male mice. Physiology \& Behavior, 1973, 10, 443-449.

Whitten, W. K. Modification of the oestrous cycle of the mouse by external stimuli associated with the male. Journal of Endocrinology, 1956, 2, 399-404.

Winans, S. S., \& Scalia, F. Amygdaloid nucleus: New afferent input from the vomeronasal organ. Science 1970, 170, 330-332.

(Received for publication July 17, 1974.) 